\begin{tabular}{|c|c|c|}
\hline 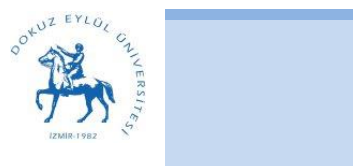 & $\begin{array}{l}\text { İzmir İktisat Dergisi } \\
\text { İzmir Journal of Economics }\end{array}$ & \\
\hline $\begin{array}{l}\text { ISSN:1308-8173 } \\
\text { Geliş Tarihi: } 23.03 .2021\end{array}$ & 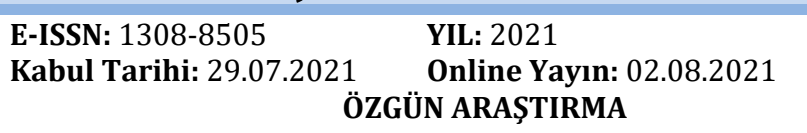 & $\begin{array}{l}\text { Cilt: } 36 \text { Sayı: } 1 \text { Sayfa: } 97-107 \\
\text { Doi: } 10.24988 / \text { ije.202136107 }\end{array}$ \\
\hline
\end{tabular}

\title{
Satınalma Gücü Paritesinin OECD Ülkeleri için Test Edilmesi: Fourier Kantil Birim Kök Testinden Bulgular
}

\author{
Oktay KIZILKAYA ${ }^{1}$, Faruk MİKE ${ }^{2}$ \\ Özet
}

Satınalma gücü paritesi, döviz kuru belirleme teorileri arasında en eski ve en tartışmalı yaklaşımlardan biridir. Bu çalışma, satınalma gücü paritesinin uzun dönemli geçerliliğini 36 OECD ülkesi için Fourier kantil birim kök testi ile incelenmeyi amaçlamaktadır. Analizler 1993:1-2018:8 aylık dönemleri kapsamaktadır. Fourier kantil birim kök testi sonuçları, 24 OECD ülkesi için satınalma gücü paritesinin geçerli olduğunu ortaya koymaktadır. Bu durum, söz konusu 24 OECD ülkesinde yer alan döviz kurlarının nispi fiyat değişikliklerine uyum sağladığııı ve satınalma gücü paritesi teorisinin bu ülkeler için güvenilir bir döviz kuru belirleme aracı olarak kullanılabileceğini ifade etmektedir.

Anahtar kelimeler: Satınalma gücü paritesi, kantil birim kök testi, fourier fonksiyonu, OECD ülkeleri

Jel Kodu: F41, C22, C50

\section{Testing the Purchasing Power Parity for the OECD Countries: Evidence from Fourier Quantile Unit Root Test \\ Abstract}

Purchasing power parity is one of the oldest and most controversial approaches among theories of exchange rate determination. This study aims to analyze the long-run validity of purchasing power parity for 36 OECD countries using the Fourier quantile unit root test. Monthly observations are used from 1995:1 to 2018:12. Fourier quantile unit root test results show that purchasing power parity is valid for 24 OECD countries. This reveals that the exchange rates in these countries adapt to the price differences and therefore, purchasing power parity theory can be used as a reliable exchange rate determination policy for the countries.

Keywords: Purchasing power parity, quantile unit root test, fourier function, OECD countries

Jel Codes: F41, C22, C50

\section{GíRiș}

Satınalma gücü paritesi teorisi, döviz kuru belirleme modellerinin en eski ve en tartışmalı yaklaşımlarından bir tanesidir. Genel olarak, döviz kuru hareketlerini, ulusal fiyat seviyeleri ve enflasyon oranlarındaki değişikliklerle ilişkilendirmektedir (Makin, 2017: 39-40). Bu teoriye göre, bir para biriminin yurtiçi satınalma gücünde bir düşüş (artış) meydana gelmesi durumunda, döviz piyasasında da aynı oranda bir değer kaybının (kazancının) gerçekleşmesi beklenmektedir (Krugman vd., 2018: 33).
Satınalma gücü paritesi teorisinin modern kökenleri, İsveçli ekonomist Gustav Cassel (1916, 1918) tarafından ortaya atılmıştır. Ancak diğer taraftan, entelektüel kökenlerine yönelik farklı yaklaşımlar bulunmaktadır. Dornbusch (1985), teorinin 16. yüzyll İspanya'sındaki Salamanca Okulu ve 1601 yılı İngiltere'sindeki Gerrard de Malynes'in yazılarına; Officer (1976), 19. yüzyılın başlarında yaşanan Banka Kısıtlama Dönemi süresince İngiliz ekonomistlerin dalgalı pound ile ilgili çalışmalarına ve Frenkel (1978) ise Wheatley ve Ricardo'nun çalışmalarına dayandığını ifade etmektedir. Genel geçerliliği

ATIF ÖNERÍsí (APA): Kızılkaya, O., Mike, F., (2021). Satınalma Gücü Paritesinin OECD Ülkeleri için Test Edilmesi: Fourier Kantil Birim Kök Testinden Bulgular. İzmir İktisat Dergisi. 36(1). 97-107. Doi: 10.24988/ije.202136107

${ }^{1}$ Doç. Dr., Malatya Turgut Özal Üniversitesi, Sosyal ve Beşeri Bilimler Fakültesi, Battalgazi / MALATYA,

EMAIL: oktay.kizilkaya@ozal.edu.tr ORCID: 0000-0002-3412-5616

2 Doç. Dr., Hakkari Üniversitesi, İktisadi ve İdari Bilimler Fakültesi, Merkez / HAKKARİ,

EMAIL: farukmike@hakkari.edu.tr ORCID: 0000-0002-9194-1679 
konusunda literatürde çok fazla tartışma yer almasına rağmen, döviz kuru hareketlerinin arkasında yatan nedenleri açıklaması anlamında oldukça önemli bir yere sahip olduğu kabul edilmektedir (Krugman vd., 2018: 33).

Bu çalışma, yaklașık 100 yıllık bir geçmişe sahip olan satınalma gücü paritesi teorisinin uzun dönemli geçerliliğini Fourier kantil birim kök testi kullanarak araştırmayı amaçlamaktadır. Çalışmada Fourier yaklaşımının kullanılmasının temel sebebi, kırılma tarihlerinin, kırılma sayısının veya kırılma yapılarının önsel olarak bilindiği varsayımının gerekli olmamasıdır. $\mathrm{Bu}$ yaklaşım, kırılma tarihleri ve kırılma sayısını doğrudan tahmin etmek yerine, bilinmeyen yapı ve bilinmeyen sayıdaki muhtemel yapısal kırılmaları yakalayabilmek için kullanılmaktadır (Tsong vd., 2016). Özellikle ulusal literatürde satınalma gücü paritesinin uzun dönemli geçerliliğini Fourier kantil birim kök testi ile inceleyen ilk çalışma olduğu düşünülmektedir.

Çalışmanın planlaması sırasıyla şu şekildedir: Birinci ve ikinci bölümde satınalma gücü paritesi ve reel döviz kuru modeline yönelik teorik açıklamalara yer verilmektedir. Üçüncü bölüm seçili ampirik literatür taramasından oluşmaktadır. Dördüncü bölümde uygulamada kullanılacak veriler ve Fourier kantil birim kök testine yönelik metodolojik açıklamalar yer almaktadır. Analiz sonuçlarının tartışılacağı beşinci bölümün ardından, çalışma sonuç ve değerlendirme bölümü ile tamamlanmaktadır.

\section{SATINALMA GÜCÜ PARİTESİ TEORISİ}

Satınalma gücü paritesi teorisi, mikro ekonomik düzeyde ifade edilen "tek fiyat kanunu"nun, makroekonomik düzeydeki karşılığı olarak nitelendirilmektedir. Buna göre tek fiyat kanunu, döviz kurlarını bireysel bir malın nispi fiyatı ile ilişkilendirirken, satınalma gücü paritesi döviz kurlarını bir mal sepetinin nispi fiyatı ile ilişkilendirmektedir. Uluslararası makroekonomi alanında ise tek fiyat kanunundan ziyade satınalma gücü paritesinin daha uygun bir çalışma konseptine sahip olduğu kabul edilmektedir (Feenstra ve Taylor, 2012: 66).

Satınalma gücü paritesi teorisi, temel olarak, mutlak ve nispi versiyon olmak üzere iki kısımda incelenmektedir. Mutlak satınalma gücü paritesine göre, nominal döviz kuru, ilgili ülkelerin fiyat endekslerinin oranına eşit olmalıdır (Gandolfo, 2016: 33). Bu yaklaşıma göre, yurtiçi fiyat seviyesinde yaşanacak nispi bir artış, söz konusu ülke para biriminin aynı oranda değer kaybı ile karşılaşmasına neden olmaktadır (Pilbeam, 2005: 302).

Mutlak satınalma gücü paritesi, döviz kurlarının uzun dönemli eğilimleri konusunda her ne kadar genel bir tahmin sağlasa da, literatürde geçerliliğine yönelik önemli eleştiriler bulunmaktadır. Bu eleştiriler genel olarak 5 başlık altında toplanabilir: (i) Fiyat endekslerinde yer alan ürünlerin, ülkelerin tüketim kalıplarına göre belirlenmesi ve farklı ağırlıklara sahip olması. (ii) Pek çok mal ve hizmetin ülkeler arasında homojen nitelikte olmaması. (iii) Mal ve hizmetlerin uluslararası serbest dolaşımını etkileyen ticaret sınırlamalarının (gümrük vergisi, tarifeler vb.) bulunması. (iv) İşlem maliyetlerinin varlığı ve (v) tüm mal ve hizmetlerin uluslararası ticaretinin mümkün olmaması (Makin, 2017: 43).

Söz konusu eleştirilerin teoriye yönelik hesaplamalarda meydana getirdiği zorluklar, satınalma gücü paritesinin alternatif yorumu olan nispi satınalma gücü paritesinin ortaya çıkmasına katkı sağlamıştır. Nispi satınalma gücü paritesi; döviz kurlarındaki yüzdesel değişimin, yurtiçi fiyat seviyesindeki yüzdesel değişim ile yurtdışı fiyat seviyesindeki yüzdesel değişim arasındaki farka eșit olması gerektiğini ifade etmektedir (Ramsaran, 1998: 102).

Satınalma gücü paritesinin her iki versiyonu da, denge döviz kurunun uzun dönemli teorileri olarak ortaya konulmuştur (Gandolfo, 2016: 334). Döviz kurlarına yönelik kısa vadede meydana gelecek şoklara karşı, fiyatların nispi olarak esnek bir yapıda olmaması, satınalma gücü paritesinin kısa dönemde geçerliliğini engellemektedir (Cuestas ve Regis, 2013: 343). 
Buna karşın satınalma gücü paritesinin uzun dönemde denge değerine tekrar getirebilecek güçler bulunmaktadır (He ve Chang: 2013, s.608).

Satınalma gücü paritesinin uzun dönemli geçerliliğini test etmeye yönelik analizler güçlü ve zayıf formlarda gerçekleştirilmektedir. Satınalma gücü paritesinin güçlü formu, reel döviz kurlarına yönelik birim kök analizleri ile test edilmektedir. Buna göre serilerin karşılaşılan şoklar karşısında uzun dönem denge değerine tekrar dönmesi (veya birim kök içermemesi) durumunda, satınalma gücü paritesinin geçerli olduğu sonucuna ulaşılmaktadır. Diğer taraftan satınalma gücü paritesinin zayıf formu ise, nominal döviz kuru ve nispi fiyat seviyeleri arasındaki uzun dönemli ilişkinin varlığını araştıran eşbütünleşme analizleri ile test edilmektedir. Seriler arasında eșbütünleșme ilişkisinin varlığ durumunda, satınalma gücü paritesinin uzun dönemde geçerli olduğuna karar verilmektedir (Mike ve Kızılkaya, 2019: 2). Bu çalışmada satınalma gücü paritesinin güçlü formu dikkate alınmaktadır.

\section{REEL DÖVIZ KURU MODELİ}

Birim kök testleri, satınalma gücü paritesinin uzun dönemli geçerliliğini test etmeye yönelik başvurulan en popüler yaklaşımlardan bir tanesidir. Buna göre reel döviz kurlarının birim kök içermesi durumunda, şokların kalıcı bir etkiye sahip olduğu ve serilerin uzun dönem denge değerine tekrar dönmeyeceğine karar verilmektedir. Diğer taraftan, reel döviz kurlarının birim kök içermemesi (durağanlık koşulunu sağlamaları) durumunda ise, şokların uzun dönemde ortadan kaybolacağı ve dengenin şokların meydana gelmesinden bir süre sonra tekrar sağlanacağı yönünde karar verilmektedir (Cuestas ve Regis, 2013: 343).
Reel döviz kuru $\left(\mathrm{Q}_{\mathrm{t}}\right)$ denklem 1'de yer alan eşitlik ile hesaplanmaktadır (Sarno ve Taylor, 2002: 66-67):

$$
\mathrm{Q}_{\mathrm{t}}=\mathrm{S}_{\mathrm{t}} \frac{\mathrm{P}_{\mathrm{t}}^{*}}{\mathrm{P}_{\mathrm{t}}}
$$

$\mathrm{S}_{\mathrm{t}}$ nominal döviz kurunu, $\mathrm{P}_{\mathrm{t}}$ ve $\mathrm{P}_{\mathrm{t}}^{*}$ ise sirasiyla yurtiçi ve yurtdışı fiyat seviyelerini göstermektedir. Reel döviz kuru logaritmik formda denklem 2'deki gibi hesaplanmakta ve denklem 3'te yer alan döviz kurlarının ortalamaya dönme modeli ile test edilmektedir:

$$
\begin{aligned}
& \mathrm{q}_{\mathrm{t}}=\mathrm{s}_{\mathrm{t}}+\mathrm{p}_{\mathrm{t}}^{*}-\mathrm{p}_{\mathrm{t}} \\
& \mathrm{q}_{\mathrm{t}}=\alpha+\beta \mathrm{q}_{\mathrm{t}-1}+\varepsilon_{\mathrm{t}}
\end{aligned}
$$

$\alpha$ sabit terimi, $\beta$ katsayı parametresini ve $\varepsilon_{\mathrm{t}}$ ise hata terimini ifade etmektedir. Denklem 3'e göre, nispi satınalma gücü paritesinin geçerli olabilmesi için $\beta=0$, mutlak satınalma gücü paritesinin geçerli olabilmesi için ise $\alpha=0$ ve $\beta=0$ koşullarının sağlanması gerekmektedir (Pentecost, 1993: 33; Doğanlar, 2006: 458).

\section{LITERATÜR TARAMASI}

Satınalma gücü paritesi teorisi, literatüre kazandırıldığı 20. yüzyılın başlarından itibaren çok sayıda teorik ve ampirik araştırmaya konu oluşturmaktadır. Özellikle Bretton Woods Sistemi'nin yürürlükten kaldırıldığı 1973 yılından itibaren, gelişen ekonometrik yöntemlerin de katkısıyla, yoğun bir ampirik literatürün oluştuğu gözlemlenmektedir. Teorinin uzun dönemli geçerliliği konusunda ortak bir görüş birliği henüz bulunmamaktadır. Oldukça geniş bir çalışma alanına sahip satınalma gücü paritesi ile ilgili olarak, bu çalışmada, büyük oranda satınalma gücü paritesinin güçlü formunu (reel döviz kuru modeli) ve Fourier yaklaşımını dikkate alan çalışmalara yönelik literatür taramasına yer verilmektedir. Seçili literatür taraması Tablo 1 'de yer almaktadır. 
Tablo 1: Seçili literatür taraması

\begin{tabular}{|c|c|c|c|}
\hline Yazar (lar) & Dönem (ler) & Yöntem (ler) & SGP geçerli mi? \\
\hline $\begin{array}{l}\text { Sarno ve Taylor } \\
\quad(1998)\end{array}$ & $\begin{array}{l}\text { 1973:1-1996:12 Aylık } \\
\text { Veri }\end{array}$ & $\begin{array}{c}\text { MADF ve JLR } \\
\text { Panel Birim Kök } \\
\text { Testleri }\end{array}$ & $\begin{array}{l}\text { SGP, G5 ülke para birimleri (sterlin, mark } \\
\text { frank, yen) için geçerlidir. }\end{array}$ \\
\hline $\begin{array}{l}\text { Papell ve Prodan } \\
\text { (2006) }\end{array}$ & $\begin{array}{l}1870-1998 \\
\text { Ylllık Veri }\end{array}$ & $\begin{array}{l}\text { Yapısal Kırılmalı } \\
\text { Birim Kök Testi }\end{array}$ & $\begin{array}{l}\text { SGP, } 16 \text { sanayileşmiş ülkenin 14'ü için } \\
\text { geçerlidir. }\end{array}$ \\
\hline Cuestas (2009) & 1992:1-2007:2 Aylık Veri & $\begin{array}{l}\text { Doğrusal Olmayan } \\
\text { Birim Kök Testia }\end{array}$ & $\begin{array}{l}\text { SGP, } 8 \text { Orta ve Doğu Avrupa ülkesi için gene } \\
\text { olarak geçerlidir. }\end{array}$ \\
\hline Lau (2009) & $\begin{array}{l}1950-1995 \\
\text { Ylllık Veri }\end{array}$ & $\begin{array}{c}\text { BNW Panel Birim Kök } \\
\text { Testi }\end{array}$ & $\begin{array}{l}\text { SGP, } 4 \text { OECD ülkesinden sadece Norveç için } \\
\text { geçerlidir. }\end{array}$ \\
\hline $\begin{array}{l}\text { Chen et al. } \\
\text { (2011) }\end{array}$ & $\begin{array}{l}\text { 1986:1-2009:10 Aylık } \\
\text { Veri }\end{array}$ & $\begin{array}{l}\text { Doğrusal Olmayan } \\
\text { Birim Kök Testib }\end{array}$ & SGP, Çin ve Tayvan için geçerlidir. \\
\hline $\begin{array}{l}\text { Lin, Chang ve } \\
\text { Chang (2011) }\end{array}$ & $\begin{array}{l}\text { 1986:1-2009:10 Aylık } \\
\text { Veri }\end{array}$ & $\begin{array}{l}\text { Fourier KPSS Birim } \\
\text { Kök Testic }\end{array}$ & $\begin{array}{l}\text { SGP, } 9 \text { Geçiş Ekonomisinden sadece } \\
\text { Litvanya için geçerlidir. }\end{array}$ \\
\hline $\begin{array}{l}\text { Liu, Su ve Zhu } \\
\quad \text { (2011) }\end{array}$ & $\begin{array}{c}\text { 1993-2008 } \\
\text { Aylık Veri }\end{array}$ & $\begin{array}{l}\text { Doğrusal Olmayan } \\
\text { Birim Kök Testib }\end{array}$ & $\begin{array}{l}\text { SGP, } 7 \text { Orta ve Doğu Avrupa ülkesinden } 3 \text { 'ü } \\
\text { (Slovakya, Romanya ve Bulgaristan) için } \\
\text { geçerlidir. }\end{array}$ \\
\hline Lu et al. (2011) & $\begin{array}{l}\text { 1995:1-2007:12 Aylık } \\
\text { Veri }\end{array}$ & $\begin{array}{l}\text { Panel SURADF Birim } \\
\text { Kök Testi }\end{array}$ & $\begin{array}{l}\text { SGP, } 16 \text { Latin Amerika ülkesinden 3'ü (E) } \\
\text { Salvador, Peru ve Surinam) için geçerlidir. }\end{array}$ \\
\hline Chang (2012) & $\begin{array}{l}\text { 1986:1-2009:10 Aylık } \\
\text { Veri }\end{array}$ & $\begin{array}{l}\text { Doğrusal Olmayan } \\
\text { Birim Kök Testi }\end{array}$ & $\begin{array}{l}\text { SGP, Çin ile } 8 \text { ticaret ortağ arasında } \\
\text { (Malezya hariç) geçerlidir. }\end{array}$ \\
\hline $\begin{array}{l}\text { Chang, Su ve Lee } \\
\text { (2012) }\end{array}$ & $\begin{array}{l}\text { 1986:1-2009:10 Aylık } \\
\text { Veri }\end{array}$ & $\begin{array}{l}\text { Doğrusal Olmayan } \\
\text { Birim Kök Testib }\end{array}$ & $\begin{array}{l}\text { SGP, } 9 \text { Doğu Asya ülkesinden 6'sı için } \\
\text { geçerlidir. }\end{array}$ \\
\hline $\begin{array}{l}\text { Liu, Zhang ve } \\
\text { Chang (2012) }\end{array}$ & $\begin{array}{l}\text { 1995:1-2011:10 Aylık } \\
\text { Veri }\end{array}$ & $\begin{array}{l}\text { Doğrusal Olmayan } \\
\text { Birim Kök Testib }\end{array}$ & $\begin{array}{l}\text { SGP, } 8 \text { Geçiş Ekonomisinden sadece } \\
\text { Romanya için geçerlidir. }\end{array}$ \\
\hline $\begin{array}{l}\text { Chang ve Tzeng } \\
\text { (2013) }\end{array}$ & $\begin{array}{l}\text { 1995:1-2008:12 Aylık } \\
\text { Veri }\end{array}$ & $\begin{array}{l}\text { Panel SURKSS Birim } \\
\text { Kök Testi }\end{array}$ & $\begin{array}{l}\text { SGP, } 9 \text { Geçiş Ekonomisinden 2'si (Estonya ve } \\
\text { Macaristan) için geçerlidir. }\end{array}$ \\
\hline $\begin{array}{l}\text { He ve Chang } \\
\text { (2013) }\end{array}$ & $\begin{array}{l}\text { 1994-2012 } \\
\text { Aylık ve Çeyreklik Veri }\end{array}$ & $\begin{array}{l}\text { Panel Fourier KSS } \\
\text { Birim Kök Testi }\end{array}$ & $\begin{array}{l}\text { SGP, çeyreklik verilerde } 14 \text { geçiş } \\
\text { ekonomisinden 7'si, aylık verilerde ise } 10^{\prime} \mathrm{u} \\
\text { için geçerlidir. }\end{array}$ \\
\hline $\begin{array}{l}\text { He, Chou ve } \\
\text { Chang (2014) }\end{array}$ & $\begin{array}{l}\text { 1994:12-2010:2 Aylık } \\
\text { Veri }\end{array}$ & $\begin{array}{c}\text { Panel Fourier SURKSS } \\
\text { Birim Kök Testi }\end{array}$ & $\begin{array}{l}\text { SGP, } 15 \text { Latin Amerika ülkesinden 14'ü } \\
\text { (Honduras hariç) için geçerlidir. }\end{array}$ \\
\hline $\begin{array}{l}\text { Bahmani- } \\
\text { Oskooee, Chang } \\
\text { ve Lee (2016) }\end{array}$ & $\begin{array}{l}\text { 1971:1-2012:4 } \\
\text { Çeyreklik Veri }\end{array}$ & $\begin{array}{l}\text { Panel Asimetrik } \\
\text { Doğrusal Olmayan } \\
\text { Birim Kök Testi }\end{array}$ & $\begin{array}{l}\text { SGP, } 20 \text { Afrika ülkesinden } 18^{\prime} \mathrm{i} \text { için } \\
\text { geçerlidir. }\end{array}$ \\
\hline $\begin{array}{l}\text { Bahmani- } \\
\text { Oskooee ve } \\
\text { Ranjbar }(2016)\end{array}$ & $\begin{array}{c}\text { 1960:1-2015:3 } \\
\text { Aylık Veri }\end{array}$ & Kantil Birim Kök Testi & $\begin{array}{l}\text { SGP, } 23 \text { OECD ülkesinden 16'sı için } \\
\text { geçerlidir. }\end{array}$ \\
\hline $\begin{array}{l}\text { Bahmani- } \\
\text { Oskooee et al. } \\
\quad(2017)\end{array}$ & $\begin{array}{l}\text { 1971:1-2012:4 } \\
\text { Çeyreklik Veri }\end{array}$ & Kantil Birim Kök Testi & SGP, 20 Afrika ülkesinden 5'i için geçerlidir. \\
\hline $\begin{array}{l}\text { Peng, Liu ve } \\
\text { Chang (2017) }\end{array}$ & $\begin{array}{l}\text { 1995:1-2015:12 Aylık } \\
\text { Veri }\end{array}$ & Kantil Birim Kök Testi & $\begin{array}{l}\text { SGP, BRICS ülkelerinin tamamı için } \\
\text { geçerlidir. }\end{array}$ \\
\hline $\begin{array}{l}\text { Bahmani- } \\
\text { Oskooee et al. } \\
\quad(2018)\end{array}$ & $\begin{array}{l}\text { 1971:1-2015:4 } \\
\text { 1980:1-2015:4 } \\
\text { Çeyreklik Veri }\end{array}$ & $\begin{array}{c}\text { Doğrusal Olmayan } \\
\text { Kantil Birim Kök Testi }\end{array}$ & $\begin{array}{l}\text { SGP, } 29 \text { Afrika ülkesinden } 15^{\prime} \mathrm{i} \text { için } \\
\text { geçerlidir. }\end{array}$ \\
\hline $\begin{array}{c}\text { Mike ve } \\
\text { Kizılkaya (2019) }\end{array}$ & $\begin{array}{c}\text { 2001:1- 2016:4 } \\
\text { Çeyreklik Veri }\end{array}$ & $\begin{array}{l}\text { Fourier Kantil Birim } \\
\text { Kök Testi }\end{array}$ & $\begin{array}{l}\text { SGP, } 12 \text { Gelişen Piyasa Ekonomisinden 6's } \\
\text { için geçerlidir. }\end{array}$ \\
\hline $\begin{array}{l}\text { Kızılkaya ve } \\
\text { Mike (2019) }\end{array}$ & $\begin{array}{c}\text { 1995:1-2017:2 Çeyreklik } \\
\text { Veri }\end{array}$ & $\begin{array}{c}\text { Fourier KPSS Birim } \\
\text { Kök Testic }^{c}\end{array}$ & SGP, 92 ülkeden 24'ü için geçerlidir. \\
\hline
\end{tabular}

Not: a: Kapetanios vd. (2003) ve Bierens (1997) , b: Caner ve Hansen (2001), c: Becker, Enders ve Lee (2006) ve d: Sollis (2009) tarafından geliştirilen birim kök testlerini ifade etmektedir. 
Tablo 2: Özet istatistikler

\begin{tabular}{|c|c|c|c|c|c|c|c|}
\hline Ülkeler & Ortalama & Maksimum & Minimum & $\begin{array}{c}\text { Standart } \\
\text { Sapma }\end{array}$ & Çarpıklık & Basıklık & $\begin{array}{l}\text { Jarque-Bera } \\
\text { (p-değeri) }\end{array}$ \\
\hline Avustralya & 4,451 & 4,715 & 4,171 & 0,141 & $-0,109$ & 2,036 & $0,003^{*}$ \\
\hline Avusturya & 4,625 & 4,721 & 4,580 & 0,026 & 1,313 & 5,535 & $0,000 *$ \\
\hline Belçika & 4,598 & 4,677 & 4,509 & 0,032 & $-0,428$ & 3,125 & $0,011^{* *}$ \\
\hline Kanada & 4,456 & 4,671 & 4,274 & 0,107 & 0,214 & 1,777 & $0,000^{*}$ \\
\hline Şili & 4,576 & 4,733 & 4,391 & 0,072 & $-0,264$ & 2,556 & $0,058^{* * *}$ \\
\hline Çek Cum. & 4,406 & 4,712 & 4,024 & 0,189 & $-0,544$ & 1,976 & $0,000^{*}$ \\
\hline Danimarka & 4,588 & 4,655 & 4,516 & 0,030 & 0,008 & 2,470 & 0,185 \\
\hline Estonya & 4,508 & 4,701 & 4,025 & 0,146 & $-1,023$ & 3,404 & $0,000^{*}$ \\
\hline Finlandiya & 4,630 & 4,764 & 4,556 & 0,041 & 0,926 & 4,051 & $0,000^{*}$ \\
\hline Fransa & 4,612 & 4,719 & 4,517 & 0,049 & 0,045 & 2,104 & $0,008^{*}$ \\
\hline Almanya & 4,633 & 4,815 & 4,516 & 0,063 & 0,575 & 3,003 & $0,000 *$ \\
\hline Yunanistan & 4,537 & 4,631 & 4,424 & 0,049 & $-0,103$ & 2,166 & $0,012^{* *}$ \\
\hline Macaristan & 4,464 & 4,748 & 4,177 & 0,143 & $-0,551$ & 2,074 & $0,000^{*}$ \\
\hline İzlanda & 4,817 & 5,103 & 4,473 & 0,141 & $-0,395$ & 2,367 & $0,002^{*}$ \\
\hline İrlanda & 4,552 & 4,747 & 4,384 & 0,082 & 0,273 & 2,332 & $0,012^{* *}$ \\
\hline İsrail & 4,618 & 4,764 & 4,436 & 0,083 & $-0,395$ & 2,291 & $0,001^{*}$ \\
\hline İtalya & 4,594 & 4,659 & 4,413 & 0,039 & $-0,823$ & 4,574 & $0,000^{*}$ \\
\hline Japonya & 4,570 & 5,016 & 4,218 & 0,178 & $-0,099$ & 2,245 & $0,026^{* *}$ \\
\hline Kore & 4,690 & 4,882 & 4,282 & 0,107 & $-0,427$ & 3,683 & $0,001^{*}$ \\
\hline Letonya & 4,525 & 4,703 & 4,193 & 0,116 & $-1,107$ & 3,532 & $0,000 *$ \\
\hline Litvanya & 4,488 & 4,668 & 3,896 & 0,179 & $-1,753$ & 5,569 & $0,000 *$ \\
\hline Lüksemburg & 4,592 & 4,636 & 4,534 & 0,024 & $-0,645$ & 2,506 & $0,000^{*}$ \\
\hline Meksika & 4,597 & 4,893 & 4,135 & 0,142 & $-0,416$ & 2,804 & $0,012^{* *}$ \\
\hline Hollanda & 4,603 & 4,669 & 4,504 & 0,038 & $-0,180$ & 2,297 & $0,024^{* *}$ \\
\hline Yeni Zelanda & 4,583 & 4,756 & 4,261 & 0,111 & $-0,994$ & 3,162 & $0,000 *$ \\
\hline Norveç & 4,552 & 4,705 & 4,397 & 0,058 & $-0,456$ & 2,718 & $0,004^{*}$ \\
\hline Polonya & 4,526 & 4,803 & 4,270 & 0,099 & $-0,305$ & 3,163 & $0,092^{* * *}$ \\
\hline Portekiz & 4,594 & 4,645 & 4,531 & 0,029 & $-0,175$ & 1,903 & $0,000 *$ \\
\hline Slovakya & 4,352 & 4,663 & 3,896 & 0,273 & $-0,421$ & 1,516 & $0,000^{*}$ \\
\hline Slovenya & 4,580 & 4,639 & 4,515 & 0,025 & $-0,407$ & 3,114 & $0,017^{* *}$ \\
\hline İspanya & 4,567 & 4,655 & 4,468 & 0,048 & $-0,318$ & 1,936 & $0,000^{*}$ \\
\hline İsveç & 4,661 & 4,869 & 4,482 & 0,090 & 0,091 & 2,592 & 0,303 \\
\hline İsviçre & 4,605 & 4,792 & 4,476 & 0,064 & 0,163 & 2,127 & $0,005^{*}$ \\
\hline Türkiye & 4,371 & 4,643 & 3,942 & 0,166 & $-0,519$ & 2,274 & $0,000^{*}$ \\
\hline İngiltere & 4,740 & 4,903 & 4,544 & 0,108 & $-0,119$ & 1,457 & $0,000 *$ \\
\hline ABD & 4,691 & 4,860 & 4,533 & 0,084 & 0,037 & 2,017 & $0,003^{*}$ \\
\hline
\end{tabular}

Not: *, ${ }^{* *}$ ve *** sırasıyla \%1, \%5 ve \%10 düzeyinde anlamlılı̆̆ı göstermektedir.

\section{VERI SETI VE EKONOMETRIK YÖNTEM}

$\mathrm{Bu}$ çalışma, satınalma gücü paritesinin uzun dönemli geçerliliğini 36 OECD ülkesi için 1995:1-2018:12 aylık dönemler doğrultusunda incelenmektedir. Çalışmada reel efektif döviz kuru (REER) serilerine yönelik Fourier kantil birim kök testi uygulanmıştır. Reel efektif döviz kurunun kullanılmasının nedeni, reel döviz kurlarına göre daha kapsamlı bir yapıya sahip olması ile ilgilidir. Diğer bir ifadeyle, ülkelerin para birimlerindeki değişimler, tek bir para birimine göre belirlemekten ziyade, ticaret partneri olan çok sayıda ülkenin dahil olduğu genel bir değere göre belirlenmektedir (He ve Chang, 2013: 605). Çalışmada kullanılan veriler, Bahmani-Oskooee ve Ranjbar (2016) çalışmasından hareketle, The Bank for International Settelments veri tabanından elde edilmiştir. Tablo 2'de çalışmada ele alınan ülkelere ait özet istatistiklere yer verilmektedir.

Tablo 2 ile sunulan Jarque-Bera test istatistiğinin p-değerlerine göre Danimarka ve İsveç hariç tüm REER serileri normal olmayan bir dağılıma işaret etmektedir. $\mathrm{Bu}$ durum, Koenker ve Xiao (2004) tarafından önerilen kantil regresyon yaklaşımını kullanmak için güçlü bir kanıt olarak karşımıza çıkmaktadır. Koenker ve Xiao (2004), verilerin normal dağılmadığı durumlarda kantil otoregresyon temelli birim kök testlerinin, geleneksel birim kök testlerinden daha yüksek güce sahip olduğunu ortaya koymuşlardır. 


\subsection{Fourier kantil birim kök testi}

Kantil regresyon yöntemi, ele alınan örneği seçilen farklı kantillerdeki birçok alt örneğe bölebilmektedir. Ayrıca, kantil regresyon yöntemini temel alan birim kök testleri kullanılarak, ele alınan kantillerde durağanlık sınaması yapılabilmektedir. Koenker ve Xiao (2004), kantil otoregresyon yaklaşımına dayanan bir birim kök testi önermişlerdir. Bununla birlikte, bu yöntem yapısal kırılmaları dikkate almamaktadır. Perron (1989)'a göre, birim kök testlerinde yapısal kırılmaların varlığını görmezden gelmek, "düşük güç" ve "yanlılık" problemlerine yol açmaktadır. Bu doğrultuda Perron (1989) tarafından geliştirilen birim kök testi, kırılma tarihlerinin dışsal olarak belirlendiği bir yapıya sahiptir. Diğer taraftan, bazı yazarlar (örneğin Zivot ve Andrews (1992), Lee ve Strazicich (2003, 2004), Narayan ve Popp (2010)) kırılma tarihlerinin içsel olarak belirlendiği birim kök testleri geliştirmişlerdir. Bu test yöntemleri, yapısal değişimleri yakalayabilmek için yapay (dummy) değişken kullanmaktadır. Buna göre kırılmalar, belirli noktalarda yer almaları ve etkilerinin ani bir şekilde gerçekleşmesi nedeniyle "keskin" bir yapıda modellenmektedir. Ancak bazı yazarlar (örneğin Leybourne, Newbold ve Vougas (1998), Kapetanios, Shin ve Snell (2003)) yapısal değişimlerin kademeli bir yapı ile gerçekleşebileceğini ileri sürerek doğrusal olmayan birim kök testleri geliştirmişlerdir. Fakat bu tip birim kök testleri, bilinen bir kırılma sayısına veya belli bir doğrusal olmayan forma sahip olduğu varsayımlarına dayanmaktadır. Becker, Enders ve Lee (2006), kırılmaların doğasının tam olarak bilinemeyeceğini, birim kök testleri için kırılmaların nerede veya kaç tane olduğunu gösterecek özel bir rehberin bulunmadığını ifade etmektedir. Bu durumdan hareketle bazı yazarlar (örneğin, Becker vd. (2006), Christopoulos ve Leon-Ledesma (2010), Enders ve Lee (2012)) ise Fourier yaklaşımını temel alan birim kök testlerini geliştirmişlerdir. Fourier yaklaşımı, bilinmeyen sayıda pürüzsüz kırılmaların varlığı durumunda kullanılabilen bir yöntemidir.

$\mathrm{Bu}$ çalışmada Bahmani-Oskooee, Chang ve Ranjbar (2017) tarafından geliştirilen Fourier kantil birim kök testi kullanılmaktadır. Stokastik bir $Y_{t}$ değişkeninin Denklem (4) ile üretildiğini varsayalım:

$$
Y_{t}=\beta_{0}+\beta_{1} \sin \left(\frac{2 \pi k t}{T}\right)+\beta_{2} \cos \left(\frac{2 \pi k t}{T}\right)+\xi_{t}
$$

Burada $\mathrm{k}$ Fourier fonksiyonunun frekans sayısını, $\mathrm{t}$ trend terimini, $\mathrm{T}$ ise örneklem boyutunu ifade etmektedir. Birim kökün varlığını ifade eden boş hipotez şu șekilde ifade edilebilir:

$$
H_{0}: \xi_{t}=\xi_{t-1}+\varepsilon_{t}
$$

Burada $\varepsilon_{t}$ 'nin sıfır ortalama ile durağan bir süreç olduğu varsayılmaktadır. Öncelikle, Denklem (4) $k=[0.1,0.2, \ldots, 4.9,5]$ için EKK yöntemi ile tahmin edilir. Kalıntı kareler toplamını minimum yapan $\mathrm{k}$ değeri uygun frekans sayısı $\left(k^{*}\right)$ olarak seçilmektedir. Daha sonra EKK kalıntıları hesaplanmaktadır:

$$
e_{t}=Y_{t}-\hat{\beta}_{0}+\hat{\beta}_{1} \sin \left(\frac{2 \pi k^{*} t}{T}\right)+\hat{\beta}_{2} \cos \left(\frac{2 \pi k^{*} t}{T}\right)
$$

İkinci aşamada, $e_{t}$ 'nin $\tau$. koşullu kantilinde birim kökün varlığı ifade eden boş hipotez Denklem (6) ile verilen kantil regresyon tahmini kullanılarak test edilmektedir:

$$
\begin{aligned}
\varphi_{e_{t}}\left(\tau \mid \xi_{t-1}\right)= & \alpha_{0}(\tau)+\rho_{1}(\tau) e_{t-1} \\
& +\sum_{\mathrm{p}=1}^{\mathrm{p}=1} \rho_{1+p}(\tau) \Delta e_{t-p}+\vartheta_{t}
\end{aligned}
$$

Burada $\varphi_{e_{t}}\left(\tau \mid \xi_{t-1}\right)$, geçmiş bilgi kümesi $\xi_{t-1}$ üzerine koşullu $e_{t}$ 'nin $\tau$. kantilini ifade etmektedir. $\alpha_{0}(\tau), \vartheta_{t}^{\prime}$ nin $\tau$. koşullu kantilidir ve bunun tahmin edilen değerleri her bir kantildeki REER şokunun büyüklügünü yakalamaktadır. $\rho_{1}(\tau)$ ise her bir kantilde $e_{t}$ 'nin ortalamaya dönme hızını ölçmektedir. Koenker ve Xiao (2004), standart ADF testinde olduğu gibi t-oranı istatistiklerinin kullanılmasını önermektedir:

$$
\mathrm{t}_{\mathrm{n}}\left(\tau_{\mathrm{i}}\right)=\frac{\hat{\mathrm{f}}\left(\mathrm{F}^{-1}\left(\tau_{\mathrm{i}}\right)\right)}{\sqrt{\tau_{\mathrm{i}}\left(1-\tau_{\mathrm{i}}\right)}}\left(R_{-1}^{\prime} P_{x} R_{-1}\right)^{0,5}\left(\hat{\rho}_{1}\left(\tau_{\mathrm{i}}\right)-1\right)
$$


Tablo 3: Fourier Kantil Birim Kök Testi Sonuçları

\begin{tabular}{|c|c|c|c|c|c|c|}
\hline \multirow{2}{*}{ Ülkeler } & \multirow{2}{*}{ Fourier QKS } & \multicolumn{3}{|c|}{ Kritik Değerler } & \multirow{2}{*}{$\mathrm{k}^{*}$} & \multirow{2}{*}{ F-istatistiğ } \\
\hline & & $10 \%$ & $5 \%$ & $1 \%$ & & \\
\hline Avustralya & $3,746^{* *}$ & 3,007 & 3,254 & 3,901 & 0,9 & 499,58 \\
\hline Avusturya & 2,628 & 3,059 & 3,323 & 3,881 & 2 & 102,27 \\
\hline Belçika & 2,673 & 3,002 & 3,251 & 3,735 & 1,8 & 131,43 \\
\hline Kanada & $5,066^{*}$ & 3,052 & 3,288 & 3,942 & 1,1 & 700,20 \\
\hline Şili & $5,087^{*}$ & 3,029 & 3,270 & 3,892 & 2 & 139,28 \\
\hline Çek Cum. & $3,081^{* * *}$ & 2,990 & 3,219 & 3,684 & 0,6 & 1769,89 \\
\hline Danimarka & $4,662^{*}$ & 3,081 & 3,313 & 3,721 & 1,5 & 198,29 \\
\hline Estonya & $4,397 *$ & 3,043 & 3,329 & 3,771 & 0,1 & 2655,36 \\
\hline Finlandiya & 2,126 & 3,020 & 3,285 & 3,806 & 0,1 & 131,18 \\
\hline Fransa & $3,778^{* *}$ & 3,074 & 3,307 & 3,811 & 0,1 & 182,87 \\
\hline Almanya & $3,511^{* *}$ & 3,057 & 3,345 & 3,824 & 0,1 & 274,21 \\
\hline Yunanistan & $3,292^{* *}$ & 2,993 & 3,204 & 3,897 & 1,3 & 391,27 \\
\hline Macaristan & 2,286 & 3,006 & 3,237 & 3,725 & 0,7 & 1170,46 \\
\hline İzlanda & $4,164^{*}$ & 2,838 & 3,060 & 3,631 & 1,3 & 141,12 \\
\hline İrlanda & $4,352^{*}$ & 3,007 & 3,205 & 3,776 & 1,3 & 569,98 \\
\hline İsrail & $3,071^{* * *}$ & 3,000 & 3,216 & 3,639 & 1,3 & 324,81 \\
\hline İtalya & 3,011 & 3,081 & 3,343 & 3,705 & 1,1 & 127,19 \\
\hline Japonya & $3,582^{* *}$ & 3,025 & 3,345 & 4,030 & 0,1 & 371,75 \\
\hline Kore & $4,838^{*}$ & 2,851 & 3,120 & 3,641 & 2,2 & 119,85 \\
\hline Letonya & $3,571^{* *}$ & 2,996 & 3,328 & 3,808 & 0,1 & 409,31 \\
\hline Litvanya & $3,781^{*}$ & 2,972 & 3,211 & 3,749 & 0,1 & 1066,97 \\
\hline Lüksemburg & $3,307^{* * *}$ & 3,147 & 3,407 & 4,045 & 1,1 & 249,01 \\
\hline Meksika & 2,768 & 2,883 & 3,155 & 3,689 & 0,7 & 248,12 \\
\hline Hollanda & 3,114 & 3,118 & 3,430 & 4,096 & 1,6 & 192,47 \\
\hline Yeni Zelanda & $3,660^{* *}$ & 3,132 & 3,384 & 3,962 & 0,9 & 127,09 \\
\hline Norveç & $3,375^{* *}$ & 3,052 & 3,272 & 3,742 & 0,1 & 137,37 \\
\hline Polonya & $4,032^{*}$ & 2,938 & 3,234 & 3,772 & 0,1 & 262,39 \\
\hline Portekiz & 1,413 & 3,058 & 3,328 & 3,986 & 1,2 & 339,15 \\
\hline Slovakya & 2,825 & 2,866 & 3,112 & 3,567 & 0,7 & 5729,05 \\
\hline Slovenya & $4,193^{*}$ & 3,196 & 3,528 & 4,019 & 0,9 & 167,06 \\
\hline İspanya & 2,256 & 3,028 & 3,280 & 3,792 & 1 & 399,93 \\
\hline İsveç & $3,288^{* * *}$ & 3,058 & 3,313 & 3,859 & 0,1 & 352,44 \\
\hline İsviçre & 2,576 & 2,955 & 3,160 & 3,721 & 1 & 201,00 \\
\hline Türkiye & $5,147^{*}$ & 2,940 & 3,174 & 3,615 & 0,8 & 463,02 \\
\hline İngiltere & 2,550 & 2,920 & 3,184 & 3,755 & 1 & 306,62 \\
\hline ABD & $3,475^{* *}$ & 3,088 & 3,329 & 3,858 & 1,3 & 784,82 \\
\hline
\end{tabular}

Not: k* optimal frekans sayısıdır. Trigonometrik terimlerin anlamlılığını test etmek için F-istatistiği kullanılmıştır. F-istatistiği için \%1, \%5 ve \%10 kritik değerler sırasıyla 6,28, 4,65 ve 3,93’tür Fourier QKS istatistiklerinin kritik değerleri yeniden örnekleme prosedürü kullanılarak ve 1000 yineleme ile hesaplanmıştır. * ** ve *** sırasıyla \%1, \%5 ve \%10 düzeyinde anlamlılığı göstermektedir. 

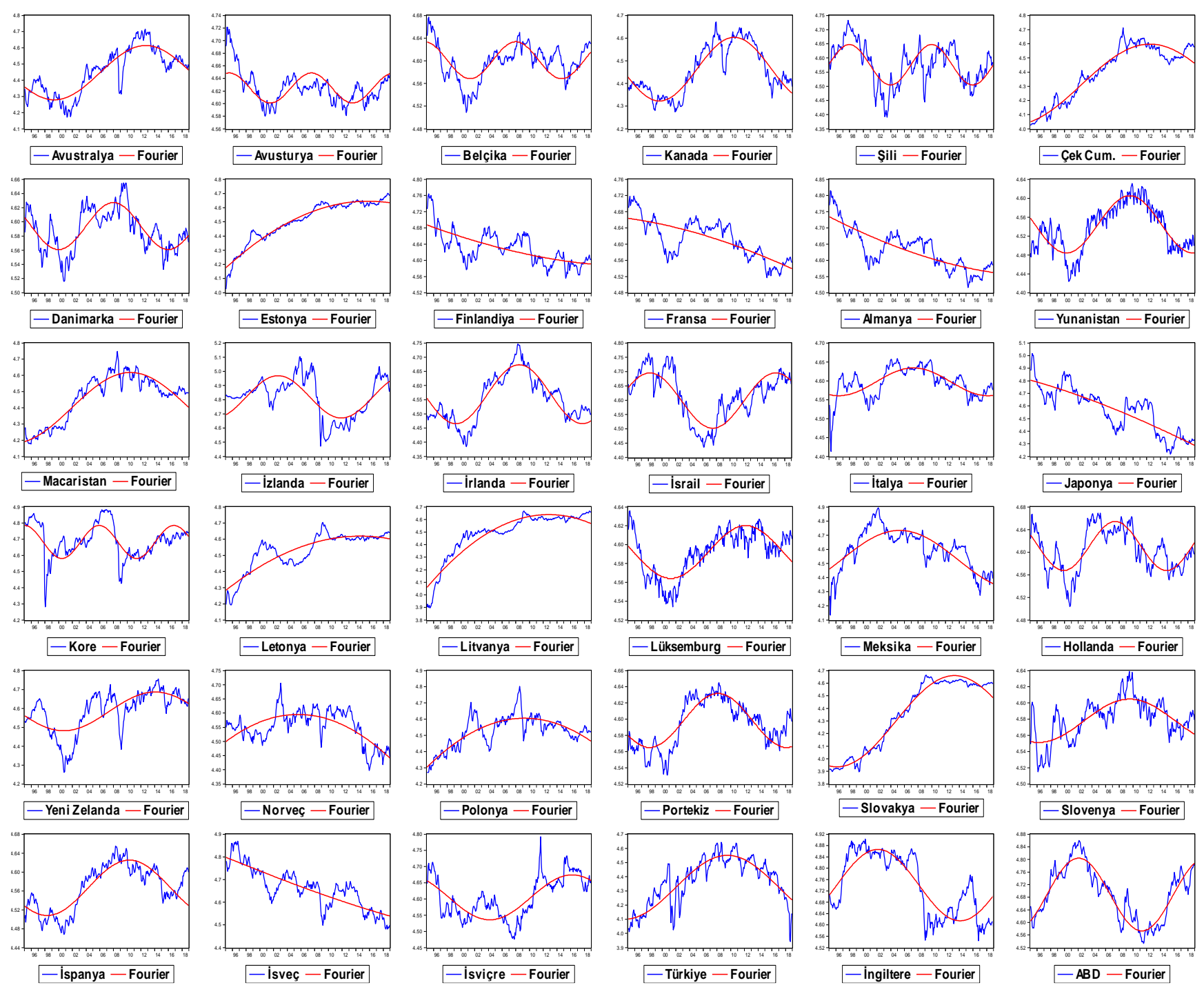

- Türkiye - Fourier
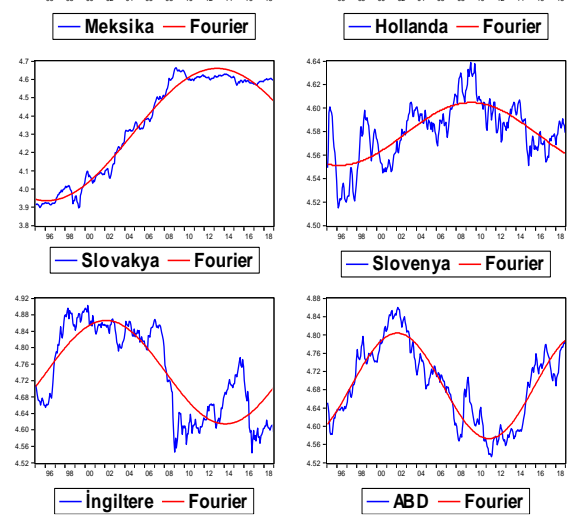

Şekil 1: REER Serileri ve Tahmin Edilen Fourier Serileri

Burada $R_{-1}$ gecikmeli bağımlı değişkenin $\left(e_{t-1}\right)$ vektörüdür, $\quad P_{x}, \quad X=\left(1, \Delta e_{t-1}, \ldots, \Delta e_{t-p}\right)$ 'e ortogonal olan uzayda izdüşüm matrisidir. Diğer taraftan, $\hat{\mathrm{f}}\left(\mathrm{F}^{-1}\left(\tau_{\mathrm{i}}\right)\right)$ ise $\mathrm{f}\left(\mathrm{F}^{-1}\left(\tau_{\mathrm{i}}\right)\right)$ 'nin tutarlı bir tahmincisidir. Koenker ve Xiao (2004) bunu Denklem (8) ile ifade etmiștir.

$$
\hat{f}\left(F^{-1}\left(\tau_{i}\right)\right)=\frac{\left(\tau_{i}-\tau_{i-1}\right)}{G^{\prime}\left(\omega\left(\tau_{i}\right)-\omega\left(\tau_{i-1}\right)\right)}
$$

Denklem (8)'de verilen $\omega\left(\tau_{i}\right)=$ $\left(\alpha_{0}\left(\tau_{i}\right), \rho_{1}\left(\tau_{i}\right), \rho_{2}\left(\tau_{i}\right), \ldots, \rho_{1+p}\left(\tau_{i}\right)\right) \quad$ ve $\quad \tau_{\mathrm{i}} \in$ $[0.1,0.9]$ 'dir. Koenker ve Xiao (2004), birim kökün varlığını ifade eden sıfır hipotezinin test edilmesi için Denklem (9) ile verilen kantil regresyona dayalı Kolmogorov-Smirnov (QKS) istatistiğini önermişlerdir:

$$
Q K S=\operatorname{Sup}_{\tau_{\mathrm{i}} \in[\text { min,max }]}\left|t_{\mathrm{n}}(\tau)\right|
$$

$\mathrm{Bu}$ çalışmada maksimum $\left|\mathrm{t}_{\mathrm{n}}(\tau)\right|$ istatistikleri seçilerek $Q K S$ istatistikleri oluşturulmuştur. Kritik değerleri üretmek için Koenker ve Xiao (2004) ve Bahmani-Oskooee, Chang ve Ranjbar'ın (2017) yeniden örnekleme prosedürleri uygulanmıştır.

\section{BULGULAR}

Bu çalışmada OECD ülkelerinde satınalma gücü paritesinin geçerliliği araştırmak amacıyla Bahmani-Oskooee, Chang ve Ranjbar (2017) tarafindan geliştirilen Fourier kantil birim kök 
testi kullanılmıștır. Fourier kantil birim kök testi sonuçları Tablo 3'te yer almaktadır.

Tablo 3'de gösterildiği gibi, OECD ülkelerinin çoğu için $\mathrm{k}^{*}$ değerleri kesirli olarak elde edilmiştir. Optimal frekans seçiminin geçerliliğini gösteren F-istatistikleri sonuçları tüm REER serileri için trigonometrik terimlerin (hem sinüs hem de kosinüs) modele dâhil edilmesi gerektiğini göstermektedir. QKS testi, her REER serisinin ortalama geri dönüş özellikleri hakkında genel bir bakış açısı sağlamaktadır. Buna göre 36 ülkenin 24'ü (Avustralya, Kanada, Şili, Çek Cumhuriyeti, Danimarka, Estonya, Fransa, Almanya, Yunanistan, İzlanda, İrlanda, İsrail, Japonya, Kore, Letonya, Litvanya, Lüksemburg, Yeni Zelanda, Norveç, Polonya, Slovenya, İsveç, Türkiye ve ABD) için boş hipotez reddedilmektedir. Dolayısıyla söz konusu ülkeler için satınalma gücü paritesi hipotezi geçerlidir. Şekil 1'de REER serileri ve tahmin edilen Fourier serileri gösterilmektedir. Verilerin trendindeki yapısal değişimler açıkça görülebilmektedir.

\section{SONUÇ}

$\mathrm{Bu}$ çalışmada satınalma gücü paritesinin uzun dönemli geçerliliğ̈i 36 OECD ülkesi için Fourier kantil birim kök testi ile incelenmiștir. Elde edilen bulgulara göre, 36 ülkenin 24'ü (Avustralya, Kanada, Şili, Çek Cumhuriyeti, Danimarka, Estonya, Fransa, Almanya, Yunanistan, İzlanda, İrlanda, İsrail, Japonya, Kore, Letonya, Litvanya, Lüksemburg, Yeni Zelanda, Norveç, Polonya, Slovenya, İsveç, Türkiye ve $A B D$ ) için birim kökün varlığını ifade eden boş hipotez reddedilmektedir. Bu sonuç Bahmani-Oskooee ve Ranjbar (2016)'ın bulguları ile benzer ş̧ekilde OECD ülkelerinin çoğu için satınalma gücü paritesinin geçerli olduğunu ortaya koymaktadır. Bu durum satınalma gücü paritesi teorisinin, büyük oranda gelişmiş ekonomilerin yer aldığı OECD ülkeleri için, başarılı bir döviz kuru belirleme aracı olarak kullanılabileceğini ortaya koymaktadır. Söz konusu ülkelerde yer alan döviz kurları, nispi fiyat değişikliklerine uygun olarak hareket etmektedir. Ayrıca döviz kurları, karşılaşılan şoklar karşısında kısa vadede denge değerinden sapma gösterse de, uzun dönemde tekrar denge noktasına dönmektedir. Söz konusu ülkelerde uygulanan istikrarlı makroekonomi politikalarının, satınalma gücü paritesinin geçerliliğine katkı sağladığı düşünülmektedir.

\section{REFERANSLAR}

Bahmani-Oskooee, M. ve Ranjbar, O. (2016). Quantile Unit Root Test and PPP: Evidence from 23 OECD Countries. Applied Economics, 48(31), 2899-2911.

Bahmani-Oskooee, M., Chang, T. ve Ranjbar, 0. (2017). The Fourier Quantile Unit Root Test with an Application to the PPP Hypothesis in the OECD. Applied Economics Quarterly, 63 (3), 295-317. doi: 10.3790/aeq.63.3.295.

Bahmani-Oskooee, M., Chang, T., Chen, T.-H. ve Tzeng, H.-W. (2017). Quantile Unit Root Test and the PPP in Africa. Applied Economics, 49(19), 1913-1921.

Bahmani-Oskooee, M., Chang, T. ve Lee, K.-C. (2016). Panel Asymmetric Nonlinear Unit Root
Test and PPP in Africa. Applied Economic Letters, 23 (8), 554-558.

Bahmani-Oskooee, M., Chang, T. Z. (M.) Elmi ve Ranjbar, O. (2018). Re-testing Prebisch-Singer Hypothesis: New Evidence using Fourier Quantile Unit Root Test. Applied Economics, 50(4), 441-454.

Bahmani-Oskooee, M., T. Chang, Z. (M.) Elmi, A. Gelan ve Ranjbar, O. (2018). Non-linear Quantile Unit Root Test and PPP: More Evidence from Africa. Applied Economics Letters, 25 (7), 465-471.

Becker, R., Enders, W. ve Lee, J. (2006). A stationarity Test in the Presence of an Unknown Number of Smooth Breaks. Journal of 


\section{O. KIZILKAYA - F. MIKEE}

Time Series Analysis, 27(3), 381-409. doi:10.1111/j.1467-9892.2006.00478.x.

Cassel, G. (1916). The Present Situation of the Foreign Exchanges. The Economic Journal, 26(103), 319-323.

Cassel, G. (1918). Abnormal Deviations in International Exchanges. The Economic Journal, 28(112), 413-415.

Chang, T. (2012). Nonlinear Adjustment to Purchasing Power Parity in China. Applied Economics Letters, 19(9), 843-848.

Chang, T. ve Tzeng, H. W. (2013). Purchasing Power Parity in Nine Transition Countries: Panel SURKSS Test. International Journal of Finance Economics, 18, 74-81.

Chang, T., C.-W. Su ve Lee, C.-H. (2012). Purchasing Power Parity Nonlinear Threshold Unit Root Test for East-Asian Countries. Applied Economics Letters, 19(10), 975-979.

Chen, T.-H., T. Chang , Y.-C. Zhang ve Lee, C.-H. (2011). Purchasing Power Parity in Mainland China and Taiwan: An Empirical Note Based on Threshold Unit Root Test. Applied Economics Letters, 18(18), 1807-1812.

Christopoulos, D. K. ve León-Ledesma, M. A. (2010). Smooth Breaks and Non-linear Mean Reversion: Post-Bretton Woods Real Exchange Rates. Journal of International Money and Finance, 29(6), 1076-1093.

Cuestas, J. C. (2009). Purchasing Power Parity in Central and Eastern European Countries: An analysis of Unit Roots and Nonlinearities. Applied Economics Letters, 16(1), 87-94.

Cuestas, J. C. ve Regis, P. J. (2013). Purchasing Power Parity in OECD Countries: Nonlinear Unit Root Tests Revisited. Economic Modelling, 32, 343-346.

Doğanlar, M. (2006). Long-run Validity of Purchasing Power Parity and Cointegration Analysis for Central Asian Countries. Applied Economics Letters, 13, 457-461.

Dornbusch, R. (1985). Purchasing Power Parity. NBER Working Paper Series, No. 1591, 1-34.
Enders, W. ve Lee, J. (2012). The Flexible Fourier Form and Dickey-Fuller Type Unit Root Tests. Economics Letters, 117(1), 196-199.

Feenstra, R. C. ve Taylor, A. M. (2012). International Macroeconomics (2nd Ed.). New York: Worth Publishers.

Frenkel, J. A. (1978). Purchasing Power Parity: Doctrinal Perspective and Evidence from the 1920s. Journal of International Economics, 8, 169-191.

Gandolfo, G. (2016). International Finance And Open-Economy Macroeconomics (2nd Ed.). Rome: Springer-Verlag Berlin Heidelberg.

He, H., M. C. Chou ve Chang, T. (2013). Purchasing Power Parity for 15 Latin American Countries: Panel SURKSS Test with a Fourier Function. Economic Modelling, 36, 37-43.

He, H. ve Chang, T. (2013). Purchasing Power Parity in Transition Countries: Sequential Panel Selection Method. Economic Modelling, 35, 604-609.

Kapetanios, G., Shin, Y. ve Snell, A. (2003). Testing for a Unit Root in the Nonlinear STAR Framework. Journal of Econometrics, 112(2), 359-379.

Koenker, R. ve Xiao, Z. (2004). Unit Root Quantile Autoregression Inference. Journal of the American Statistical Association, 99(467), 775-787. doi: 10.1198/016214504000001114.

Kızılkaya, O. ve Mike, F. (2019). Reel Döviz Kurlarının Fourier Durağanlık Analizi ile Test Edilmesi. Journal of Yasar University, 2019, 14(53), 21-30.

Krugman, P. R., M, Obstfeld ve Melitz, M. (2018). International Finance: Theory ve Policy (11th Ed.). London: Pearson Education.

Lau, C. K. M. (2009). A More Powerful Panel Unit Root Test with an Application to PPP. Applied Economics Letters, 16(1), 75-80. doi: 10.1080/13504850701735815.

Lee, J., ve Strazicich, M. C. (2003). Minimum Lagrange Multiplier Unit Root Test with Two Structural Breaks. Review of Economics and Statistics, 85(4), 1082-1089. 
Lee, J. ve Strazicich, M. C. (2004). Minimum LM Unit Root Test with One Structural Break. Manuscript, Department of Economics. Appalachian State University, 1-16.

Leybourne, S., Newbold, P. ve Vougas, D. (1998). Unit Roots and Smooth Transitions. Journal of Time Series Analysis, 19(1), 83-97.

Lin, S.-Y., H.-J. Chang ve Chang, T. (2011). Revisiting Purchasing Power Parity for Nine Transition Countries: A Fourier Stationary Test, Post-Communist Economies, 23(02), 191-201.

Liu, S., D. Zhang ve Chang, T. (2012). Purchasing Power Parity-Nonlinear Threshold Unit Root Test for Transition Countries. Applied Economics Letters, 19(18), 1781-1785.

Liu, Y.-S., C.-W. Su ve Zhu, M.-N. (2011). Purchasing Power Parity with Threshold Effects for Central and Eastern European Countries. Applied Economics Letters, 18, 1801-1806.

Lu, Y.-C. R., T. Chang, C.-C. Chiu ve Tzeng, H.-W. (2011). Revisiting Purchasing Power Parity for 16 Latin American Countries: Panel SURADF Tests. Applied Economics Letters, 18(3), 251255.

Makin, A. J. (2017). International Money and Finance. New York: Routledge.

Mike, F. ve Kızllkaya, O. (2019). Testing the Theory of PPP for Emerging Market Economies that Practice Flexible Exchange Rate Regimes. Applied Economics Letters, 26(17), 1411-1417.

Narayan, P. K. ve Popp, S. (2010). A New Unit Root Test with Two Structural Breaks in Level and Slope at Unknown Time. Journal of Applied Statistics, 37(9), 1425-1438.

Officier, L. H. (1976). The Purchasing-PowerParity Theory of Exchange Rates: A Review Article. International Monetary Fun Staff Papers, 1-60.

Papell, D. H. ve Prodan, R. (2006). Additional Evidence of Long-Run Purchasing Power Parity with Restricted Structural Change. Journal of Money, Credit and Banking, 38(5), 1329-1349.

Peng, H., Z. Liu ve Chang, T. (2017). Revisiting Purchasing Power Parity in BRICS Countries using more Powerful Quantile Unit-Root Tests with Stationary Covariates. Communications in Statistics-Theory and Methods, 46(20), 1005110057.

Pentecost, E. J. (1993). Exchange Rate Dynamics: A Modern Analysis of Exchange Rate Theory and Evidence. UK: Edward Elgar Publishing.

Perron, P. (1989). The Great Crash, the Oil Price Shock, and the Unit Root Hypothesis. Econometrica: Journal of the Econometric Society, 57(6), 1361-1401.

Pilbeam, K. (2005). Finance and Financial Markets (2nd Ed.). New York: Palgrave MacMillan.

Ramsaran, R. F. (1998). An Introduction to International Money and Finance. London: MacMillan Press.

Sarno, L. ve Taylor, M. P. (1998). Real Exchange Rates under the Recent Float: Unequivocal Evidence of Mean Reversion. Economics Letters, 60, 131-137.

Sarno, L. ve Taylor, M. P. (2002). Purchasing Power Parity and the Real Exchange Rate. IMF Staff Papers, 49(1), 65-105.

Taylor, M. P. (2006). Real Exchange Rates and Purchasing Power Parity: Mean-Reversion in Economic thought. Applied Financial Economics, 16, 1-17.

Tsong, C.-C., C.-F. Lee, L.-J. Tsai ve Hu, T.-C. (2016). The Fourier Approximation and Testing for the Null of Cointegration. Empirical Economics, 51 (3), 1085-1113. doi: 10.1007/s00181-015-1028-6.

Zivot, E. ve Andrews, D. W. K. (2002). Further Evidence on the Great Crash, the Oil-Price Shock, and the Unit-Root Hypothesis. Journal of Business ve Economic Statistics, 20(1), 25-44. 